\title{
Evaluation of copper compounds using automated multivariate statistical phase analysis of EDX spectral imaging data
}

\section{E D X多変量イメージ解析を用いた自動相分離法による銅化合物の存在形態の評価}

\author{
Mitsuhiro WADA \\ Corporate R\&D Center, Mitsui Mining \& Smelting Co., Ltd., 1333-2 Haraichi, Ageo-shi, Saitama \\ 362-0021 \\ TEL: x81-48-775-3211 FAX:x81-48-775-6373 e-mail:m_wada@mitsui-kinzoku.cp.jp
}

( Received 17, March 2010 Accepted 1, April 2010 )

\begin{abstract}
In ferrous metal smelting operations, each element is refined from very complex compound material in which the major elements are $\mathrm{Cu}, \mathrm{Zn}$ and $\mathrm{Pb}$. Especially in smelting $\mathrm{Cu}$, it is very important to understand the complex morphology of the various compounds in the raw material because of its very diversity. This detailed understanding of the complex morphology is necessary for the high purification process of each element and to improve the refining efficiency. Currently, ICP, XRD and EPMA are used for the evaluation of the raw materials. However, ICP and XRD can provide information only about average composition and EPMA requires highly experienced analysts to operate the instrument and evaluate a mixed compound material. In this study we analyzed Cu-compound raw material by the auto phase analysis method using the multivariate statistical analysis of EDX spectral imaging data (Thermo Scientific COMPASS). We analyzed the phases which were extracted objectively by present method mentioned above. As the results of the analysis of the EDX spectral imaging data acquired for 30 minutes, we could confirm the 15 phases including $\mathrm{Cu}$-Sn alloy (as the major component), $\mathrm{Cu}$ sulfide and compounds with rare elements such as $\mathrm{Sb}$ and As, and we recognized that those phases are mixed with the typical distribution.
\end{abstract}

Keywords : Cu compound, SDD-EDX, Multivariate statistical analysis, Ferrous metal

\section{INTRODUCTION}

非鉄金属製鍊では、 $\mathrm{Cu}$ や $\mathrm{Zn} 、 \mathrm{~Pb}$ を主とする非常に複 雑な化合物から、各元素の製錬を行っている。1-3この金 属製錬工程や資源開発での解析においては、原料や製錬 過程で生じる金属鉱物の存在形態を把握することが極め て重要である。中でも $\mathrm{Cu}$ は、多様な化合物を形成する ために、複雑な存在形態を正しく理解することに手間と 時間を費やしている。なぜならば、詳細な存在形態を知 りえることが、製錬効率を向上させ各元素の高純度化が 達成できるためである。

これら化合物の評価については、X線回折法（XRD） による結晶構造解析と、誘導発光プラズマ法 (ICP) 元 素定性定量分析、X線マイクロプローブ顕微鏡（EPMA） による元素分布および定量観察、そして金属顕微鏡を用 いた色調評価による評価が一般的である。しかし XRD
と ICP では、化合物の平均的な状況しか把握できず、具 体的な存在形態が把握できるのは主要な相に限られてい る。一方これらの化合物では、10２0 に及ぶ元素が 10 前後の複雑な相を形成しているために、EPMA による元 素分析技術が実施されてきたが、多数の元素を定量評価 する際には、1 試料あたり数時間にわたる評価が必要と なっている。加えて、化合物の存在形態について分布状 況を把握するためには、色調評価と EPMA 評価結果を複 合して判断する必要性があり、評価者の解析経験が必要 とされるため、最近では客観的な評価が検討され始めて いる。 4

一方、近年ではエネルギー分散X線分析（EDX）検出 器において Silicon Drift Detector（SDD）型が開発され、 $\mathrm{X}$ 線の検出効率が向上したことで計測時間の短縮化が図 られた。また、これらの材料系においては、X線励起電 
圧が非常に近い元素が数多く存在しているため、波長分 散型の EPMA が一般的に用いられてきた。しかし評価解 析ソフトウェアについてもスペクトルマッピング法の一 般化と、定量マッピング法の精度向上し、EPMA と遜色 のない結果を得られるようになってきた。さらに多変量 解析といった数学的解析による解析手法も EDX に取り 入れられ、EDX スペクトルの自動相分離解析技術等が確 立されてきた。

本研究では、評価時間の短縮化と客観性を向上させる ために、SDD 型の高速 EDX 検出器と自動相分離解析が 可能な COMPASS を用いて製錬原料となる $\mathrm{Cu}$ 化合物の 評価を行い、短時間測定ながら複雑な相分布状況の把握 行ったので報告する。

\section{EXPERIMENTAL DETAILS}

本報告では、銅鉛製錬過程において粗鉛を取り出した 後の初期段階に大量発生する $\mathrm{Cu}$ 化合物について評価を 行った。Cu 化合物の粉末試料について結晶構造はXRD、 全元素定性分析は ICP によってそれぞれ評価を実施した。 そして、当該試料中の各元素の分布状態、ならびに存在 形態については、電界放出型走査電子顕微鏡（FE-SEM） -EDX によって評価を行った。評価視野は、金属顕微鏡 および SEM-EDX ともに、 $230 \times 180 \mu \mathrm{m}$ 四方を測定した。 FE-SEM は Carl-Zeiss 社 ULTRA55 を使用した。EDX は、 SDD 型エネルギー分散X線検出器（SDD-EDX : サーモ フィッシャーサイエンティフィック社製 Ultra-Dry）を用 いて計測し、多変量イメージ解析ソフトウェア（サーモ フィッシャーサイエンティフィック社製 COMPASS）を 用いて、計測同時自動相分離解析技術を用いて実施した。 なお EDX 用評価は、当該粉末試料を樹脂包埋し、研磨 後 Cコーティングを行ったものについて実施した。また、 今回の EDX 計測時間は、30 分間とした。

\section{RESULTS}

まずはじめに、XRD と ICP による評価結果を述べる。 $\mathrm{ICP}$ による全元素定性分析から、 $\mathrm{Cu}, \mathrm{As}, \mathrm{Sn}, \mathrm{Sb}, \mathrm{Pb}, \mathrm{Na}, \mathrm{Al}$, $\mathrm{Si}, \mathrm{Fe}, \mathrm{Ni}, \mathrm{Zn}, \mathrm{Se}, \mathrm{In}, \mathrm{Bi}$ の 14 元素が検出された。

次に $\mathrm{Cu}$ 化合物の XRD 回折パターンを Fig.1 に示す。 この結果から、主成分は金属 $\mathrm{Pb}, \mathrm{PbS}, \mathrm{PbO}, \mathrm{Cu}_{3} \mathrm{Sn}$, そし て $\mathrm{SnO}_{2}$ であることがわかった。しかしこの構造解析結 果からでは、 $\mathrm{Pb}$ 系化合物の回折ピークとそれらによるバ ックグラウンドが非常に高いために、微量な相や非晶質 相については検出できていない可能性がある。また、ICP で検出された元素の中でも、Sb や As などについては、 $\mathrm{Cu}, \mathrm{Ni}$ や $\mathrm{Zn}$ などに固溶することが知られており、それ
らの存在形態について明らかにすることは Fig.1の XRD 回折パターンからだけでは判断不可能である。

Photo 1 は、XRD 評価を行った試料の断面研磨写真で ある。写真の色調評価により、主要な相の存在状態はお おむね特定可能であり、Photo 1 中の a)は金属 $\mathrm{Pb}$ 、b)は $\mathrm{Cu}-\mathrm{Sn}$ 合金、 $\mathrm{c})$ は $\mathrm{Pb}$ 硫化物、そして d) $\mathrm{Cu}$ 硫化物と判定 した。

Photo 1 と同等の視野において、FE-SEM-EDX を用い て観察した二次電子（SE）像と、X線の定量マッピング を実施した各元素の分布状況を Fig. 2 に示す。この元素 分布状況（Fig. 2) は、従来のピーク強度を用いたマッピ ング（Fig. 3）では、他の元素の影響を受けて正しく表示 されなかった $\mathrm{S}$ や $\mathrm{Sb}, \mathrm{Ca}, \mathrm{Al}$ についても、本来の分布状 況を示している。

さらにこれら EDX の計測時に同時進行にて解析を実 施していた多变量イメージ解析法による自動相分離解析 を行った結果について、各成分の分布像を Fig. 4-1〜4-16 に示す。Fig. 4-1〜4-16 の枝番号は、多変量イメージ解析 における寄与率の高い順に示しており、自動相分離解析

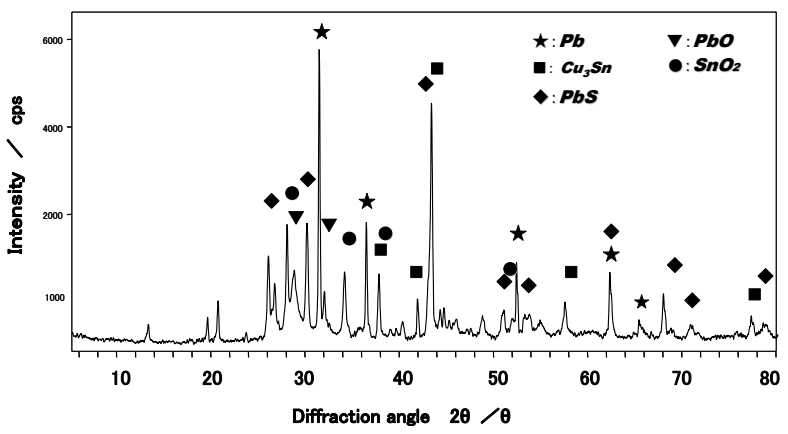

Fig. 1. The X-ray diffraction patarn of $\mathrm{Cu}$-compound raw material.

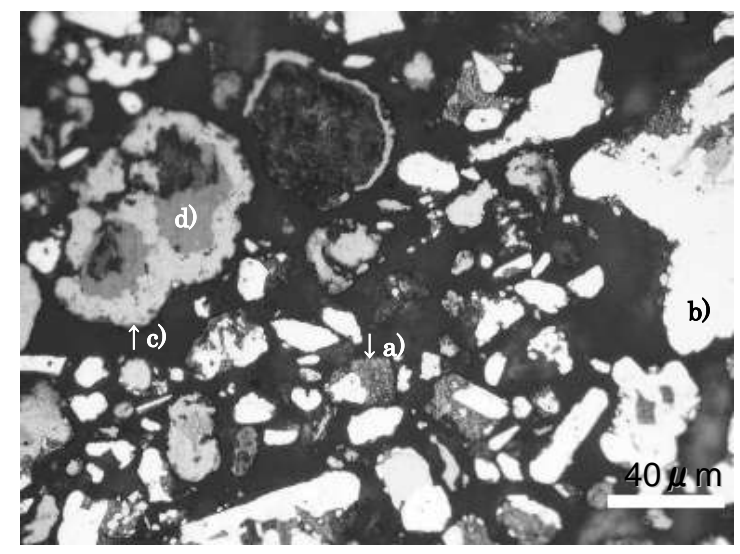

Photo 1. The photo of $\mathrm{Cu}$-compound raw material by metallurgical microscope. 

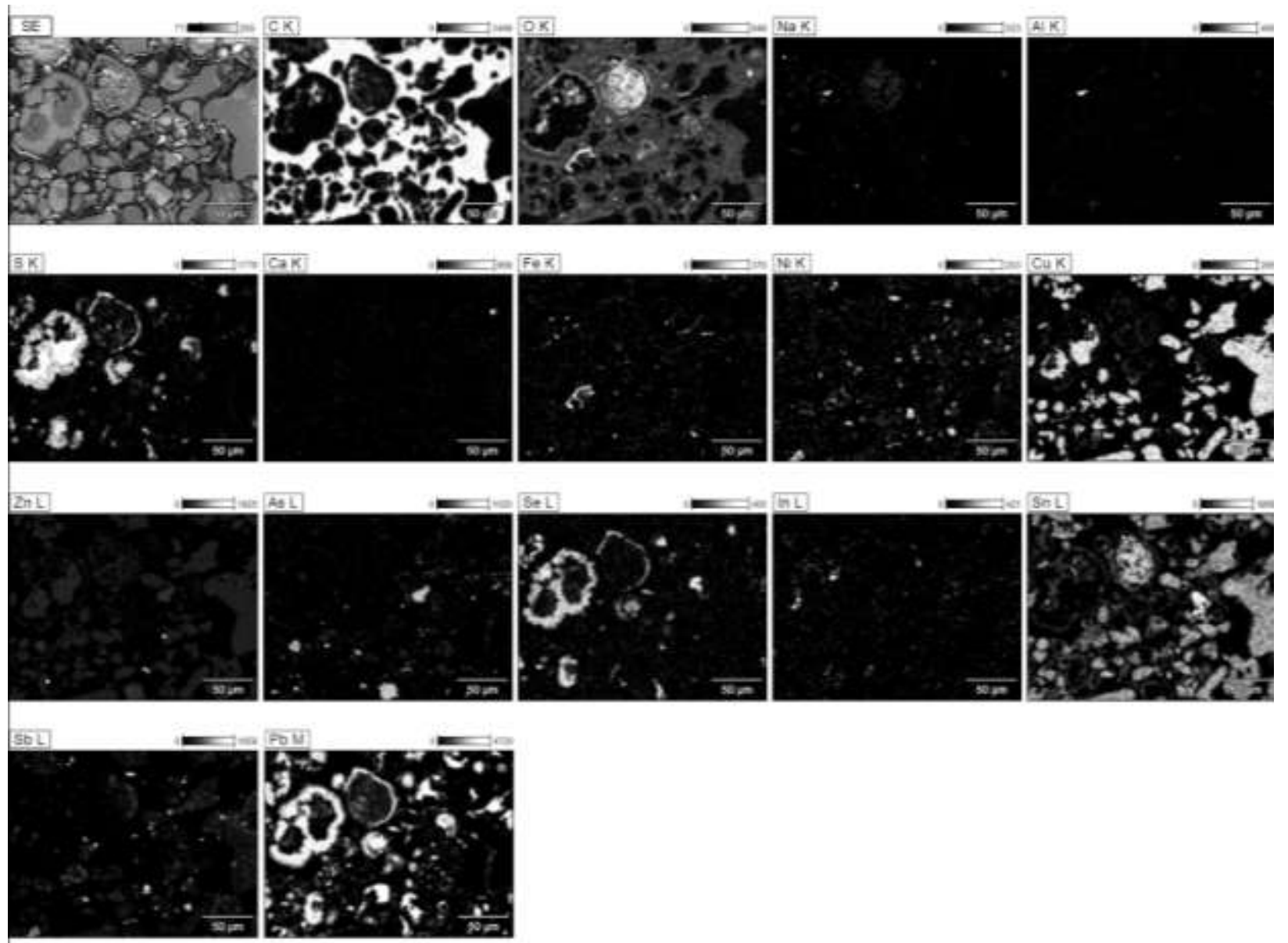

Fig. 2. SE and X-ray images for $\mathrm{Cu}$-compound raw material by EDX quantitative spectral mapping.

によって 16 の成分が検出された。さらにこれらの分布像 で示した各成分の分布範囲から抽出した EDX スペクト ルについて、定量分析を行った結果も共に示す。これら の結果から、第 2 成分は試料の包埋樹脂であることから

(Fig.4-2)、今回の $\mathrm{Cu}$ 化合物には 15 相が存在している ことが明かになった。

これらの結果より、今回評価した $\mathrm{Cu}$ 化合物について は、以下のような特徴をもった各元素の存在形態と分布 状況であることが明らかになった。

1) 主相は $\mathrm{Cu}-\mathrm{Sn}$ 合金相である。

2) $\mathrm{Cu}-\mathrm{Sn}$ 合金相は金属 $\mathrm{Pb}$ との結合相として存在して いる。

3） $\mathrm{Cu}-\mathrm{Sn}-\mathrm{Pb}$ 等からなる複合酸化物と $\mathrm{Cu}$ 硫化物の結 合相を核として、Pb 硫化物が包埋する状態で存在 している。

4) EPMA での検出は評価前に予め予想していないと 困難と思われる極わずかなガラス質成分相やフッ 酸 $\mathrm{Ca}$ 相の存在も確認された。

5) 一般的な $\mathrm{EDX}$ では評価が困難な $\mathrm{Pb}$ 中の $\mathrm{S}$ や、 $\mathrm{Cu}-\mathrm{Sn}$ 合金中の微量な $\mathrm{As}, \mathrm{Se}, \mathrm{In}, \mathrm{Sb}$ についても特
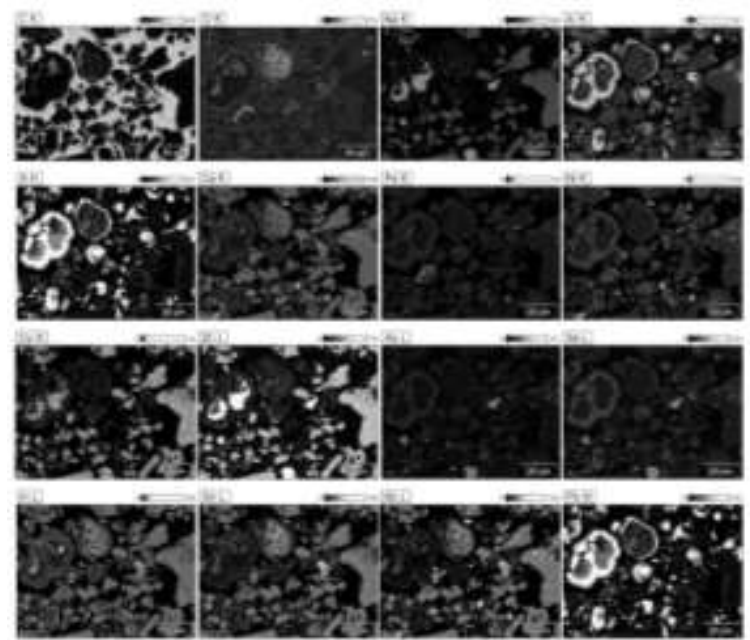

Fig. 3. X-ray images for $\mathrm{Cu}$-compound raw material by EDX intensity mapping.

徵的な分布状態を評価し把握できた。 


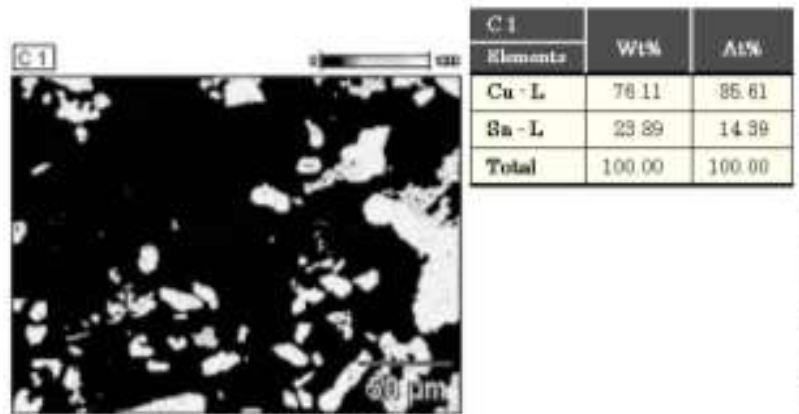

Fig. 4-1. The phase map C1 by the auto phase analysis.

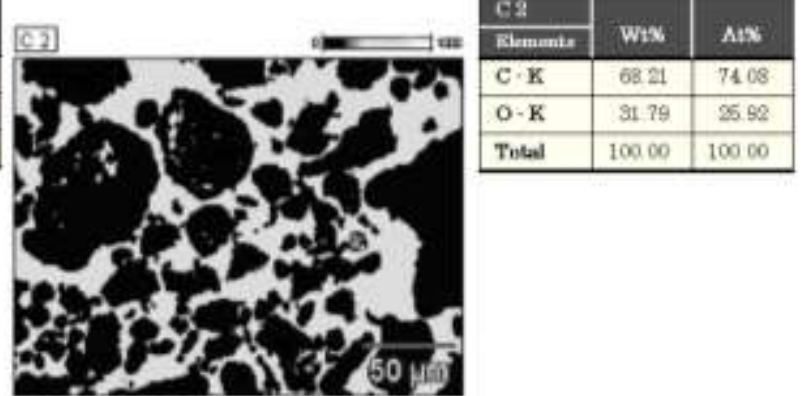

Fig. 4-2. The phase map C2 by the auto phase analysis.
Table 1-3. Chemical composition of $\mathrm{C} 3$ area.

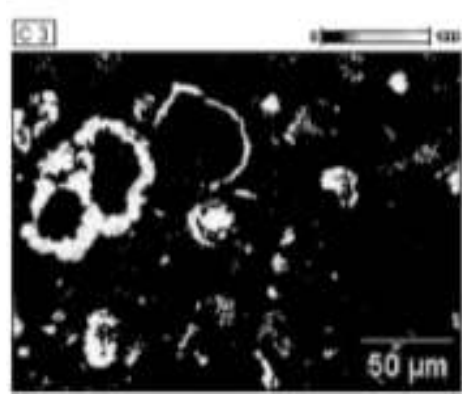

Fig. 4-3. The phase map C3 by the auto phase analysis.

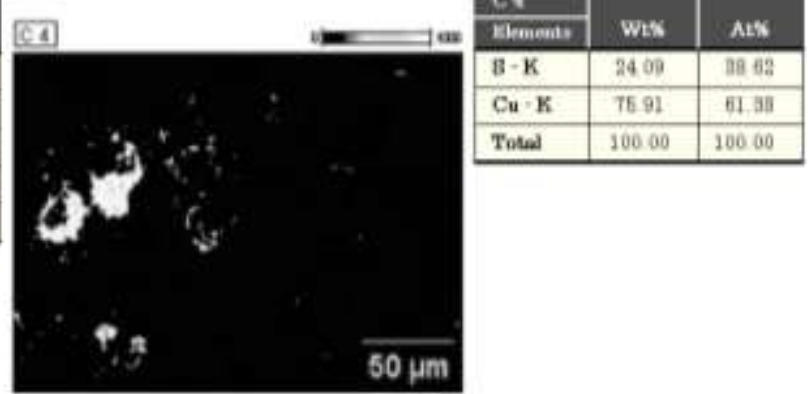

Fig. 4-4. The phase map C4 by the auto phase analysis.

Table 1-6. Chemical composition of C6 area.

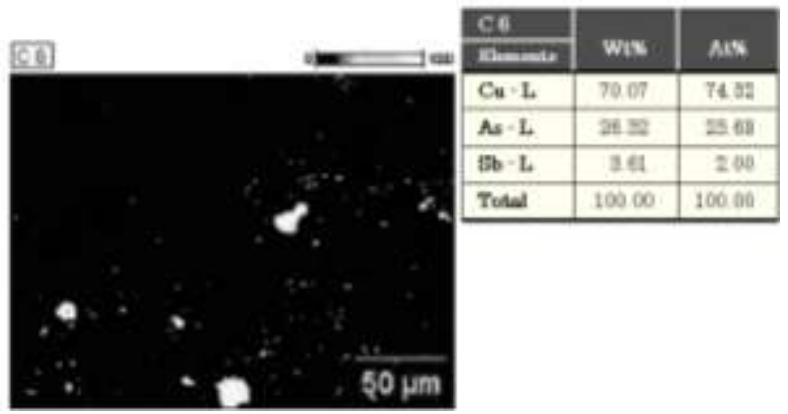

Fig. 4-6. The phase map C6 by the auto phase analysis.

Table 1-8. Chemical composition of C8 area.

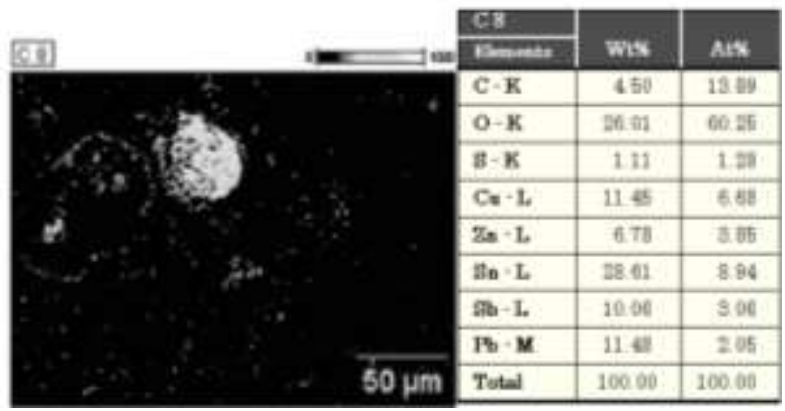

Fig. 4-8. The phase map C8 by the auto phase analysis.

Fig. 4-7. The phase map C7 by the auto phase analysis. 
Table 1-9. Chemical composition of C9 area.

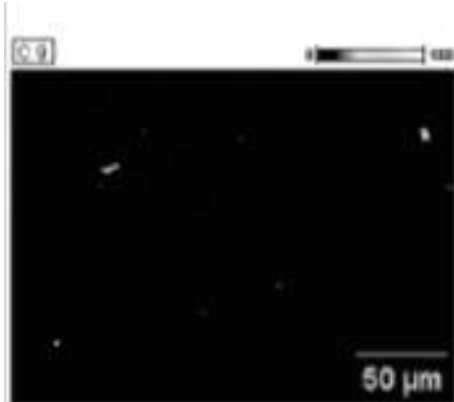

Fig. 4-9. The phase map C9 by the auto phase analysis.

Table 1-11. Chemical composition of $\mathrm{C} 11$ area.

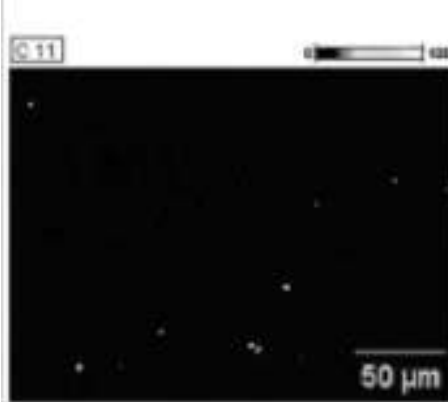

Fig. 4-11. The phase map C11 by the auto phase analysis.

Table 1-13. Chemical composition of $\mathrm{C} 13$ area.

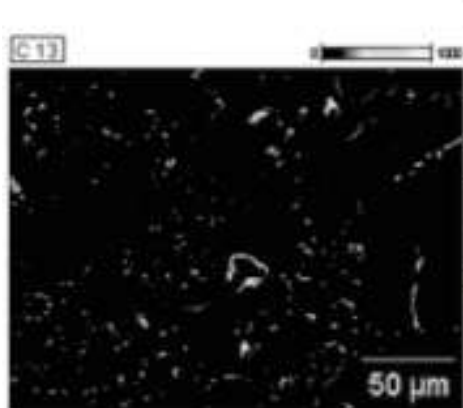

\begin{tabular}{|c|c|c|}
\hline C19 & \multirow[b]{2}{*}{ WLX } & \multirow[b]{2}{*}{ ALS } \\
\hline netsents & & \\
\hline C. $\mathrm{E}$ & 2956 & $122 \mathrm{E}$ \\
\hline O-K & 18.81 & 29.64 \\
\hline S-K & $\alpha 04$ & 0.05 \\
\hline $\mathrm{Sn}-\mathrm{L}$ & 2125 & 459 \\
\hline $\mathrm{F}-\mathbf{M}$ & 3053 & 373 \\
\hline Tatal & 10000 & 10000 \\
\hline
\end{tabular}

Fig. 4-13. The phase map C13 by the auto phase analysis.

Table 1-15 Chemical composition of C15 area

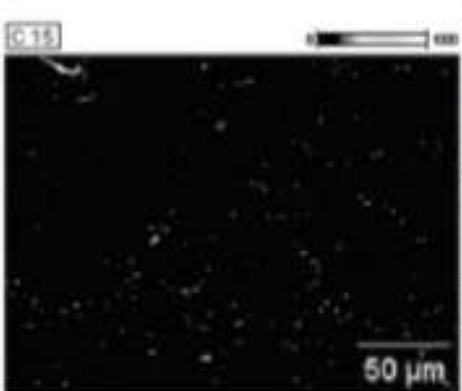

\begin{tabular}{|c|c|c|}
\hline CIf & & \\
\hline Elimenterst & Wis & AtX \\
\hline$C-\mathrm{K}$ & 1200 & 6020 \\
\hline O. $\mathbf{K}$ & 42 & 1316 \\
\hline $\mathrm{Cu}-\mathbf{L}$ & 2012 & 156 \\
\hline $8 n-1$ & 1873 & 851 \\
\hline $\mathrm{Atb}-\mathrm{L}$ & 1040 & 427 \\
\hline $\mathrm{Fb}-\mathrm{M}$ & 3028 & 800 \\
\hline Total & 100.00 & 10000 \\
\hline
\end{tabular}

Fig. 4-15. The phase map C15 by the auto phase analysis.
Table 1-10. Chemical composition of $\mathrm{C} 10$ area.

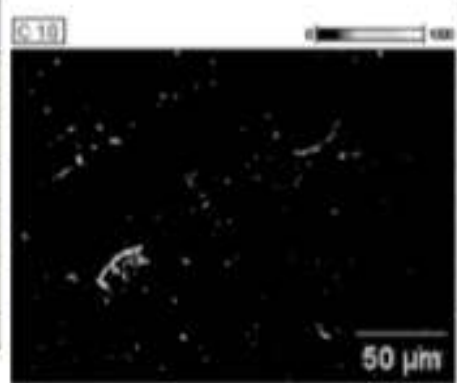

\begin{tabular}{|c|c|c|}
\hline $\mathrm{ClO}$ & & \\
\hline Whement: & Whes & Mis \\
\hline$c-K$ & 497 & 1475 \\
\hline O.K & 2114 & 53.57 \\
\hline$Y_{e} \cdot \mathbf{K}$ & 2422 & 1756 \\
\hline $2 \mathbf{a}-\mathrm{L}$ & 513 & ata \\
\hline tis-1. & 1425 & 487 \\
\hline $\mathrm{Pb}-\mathrm{M}$ & 3080 & 605 \\
\hline Tutal & 10060 & 10000 \\
\hline
\end{tabular}

Fig. 4-10. The phase map C10 by the auto phase analysis.

Table 1-12. Chemical composition of C12 area.

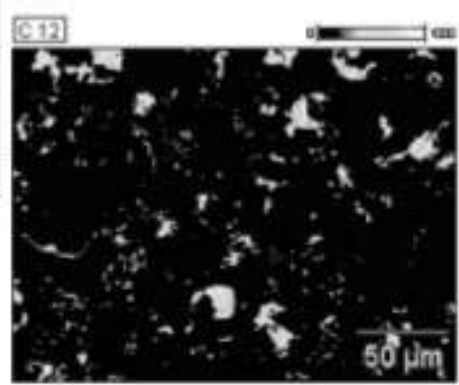

\begin{tabular}{|c|c|c|}
\hline $\mathrm{Cl}_{212}$ & & \\
\hline Xienmets & Whas & Als \\
\hline $\mathrm{C}-\mathrm{B}$ & 350 & 3388 \\
\hline O. K & 209 & 1478 \\
\hline $\mathrm{Fb}-\mathrm{M}$ & 9438 & 51.45 \\
\hline Total & 10000 & 100,00 \\
\hline
\end{tabular}

Fig. 4-12. The phase map C12 by the auto phase analysis.

Table 1-14. Chemical composition of C14 area.

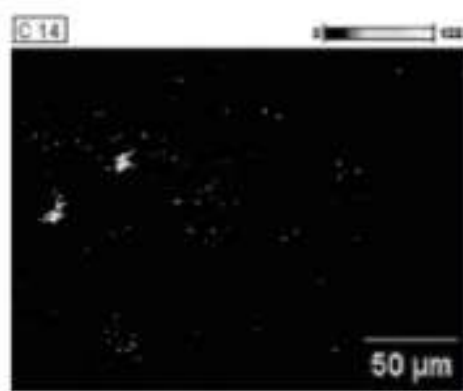

\begin{tabular}{|c|c|c|}
\hline & whes & s.8. \\
\hline Remantr & & \\
\hline$C \cdot \mathrm{K}$ & 2.55 & 9.88 \\
\hline O-K & 1745 & 50.50 \\
\hline S.E & 414 & 598 \\
\hline $\mathrm{Cu}-\mathrm{L}$ & 2828 & 16.97 \\
\hline In $-\mathrm{L}$ & 8.70 & 5. 91 \\
\hline $3 n-1$. & 734 & 296 \\
\hline $8 b-1$ & 1276 & 485 \\
\hline$F_{b}-\mathbf{M}$ & 2271 & 509 \\
\hline Tobal & 10000 & 100.00 \\
\hline
\end{tabular}

Fig. 4-14. The phase map C14 by the auto phase analysis.

Table 1-16Chemical composition of C16 area.

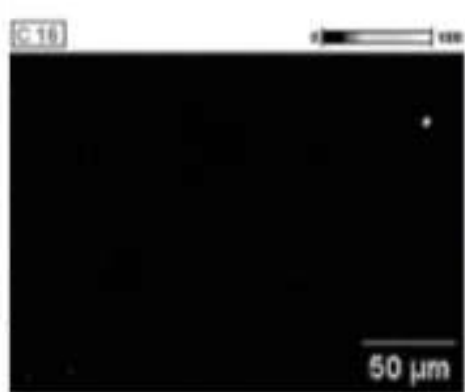

\begin{tabular}{|c|c|c|}
\hline CI6 & \multirow[b]{2}{*}{ Whx } & \multirow[b]{2}{*}{ Ais } \\
\hline tinmedy & & \\
\hline$C \cdot K$ & 750 & 12.67 \\
\hline $0 . \mathrm{K}$ & 1822 & 17.84 \\
\hline $\boldsymbol{V} \cdot \boldsymbol{K}$ & $\triangle A T E$ & 5462 \\
\hline $\mathrm{Ca}-\mathrm{K}$ & 29.73 & 15.47 \\
\hline Tatal & 10000 & 10000 \\
\hline
\end{tabular}

Fig. 4-16. The phase map C16 by the auto phase analysis. 
これらの評価結果により、この $\mathrm{Cu}$ 化合物の製錬効率 を向上させ、各元素の高純度化を達成するための手順に ついて非常に検討し易くなった。また、今回の計測時間 は30 分であったが、十分な結果であることからも、製錬 工程への迅速なフィードバックが可能になった。さらに、 当手法を用いて各製鍊工程内に発生する生成物を評価す ることで、それらの検証を簡便に実証することが可能と なった。

\section{CONCLUSION}

多変量イメージ解析手法（COMPASS）を用いて評価 することで、複雑な $\mathrm{Cu}$ 化合物について各化合物の存在 形態と分布状況を容易に把握することができた。

\section{ACKNOWLEDGEMENTS}

本研究を遂行するにあたり、SDD-EDX 検出器
(Ultra-Dry) と、多変量イメージ解析ソフトウェア （COMPASS）での自動相分離解析に関して御協力賜り ました、サーモフィッシャーサイエンティフィック株式 会社鈴木様に深く感謝いたします。

\section{REFERENCES}

${ }^{1} \mathrm{~W}$. Yan and W. L. Cai, Huagong Yejin, 21 3, 298-301 (2000).

${ }^{2}$ W. Yan, Huagong Yejin, 21 4, 403-406 (2000).

3 T. deng and Z. Wen, Huagong Yejin, 213 , 236-240 (2000).

${ }^{4}$ E. Ochi and T. Sako, Proc. 56th Conf. on Field Personnel Mines and Smelter - Analysis Section -, Tokyo, June 1996, Japan Mining Industry Association 47-53 (1996). 